\title{
QUALIDADE E CARACTERÍSTICAS FÍSICAS DE OVOS COMERCIAIS
}

\author{
HONORATO, Claucia Aparecida ${ }^{1}$ \\ SEABRA, Bruna Soares ${ }^{2}$ \\ SIQUEIRA, Mayara Schueroff ${ }^{1}$ \\ MELGAREJO, Marluci Rodrigues ${ }^{1}$ \\ FRAGA, Thiago Leite $^{1}$
}

\begin{abstract}
RESUMO: O ovo é um alimento com alto valor nutricional, contendo muitas proteínas, vitaminas e minerais, e com baixo custo, o que estimula o consumo. Por ser um produto perecível é necessário armazená-lo corretamente para que este produto possa estar viável para o consumo por longo período. O objetivo desta pesquisa foi avaliar a qualidade interna de ovos brancos e vermelhos armazenados em temperatura ambiente e sob refrigeração durante 25 dias de armazenamento. Os ovos brancos e vermelhos armazenados em temperatura ambiente apresentam perda de viabilidade aos 15 dias de estocagem, já os ovos armazenados em geladeira apresentam perda de viabilidade com 25 dias de estocagem. A viabilidade dos ovos brancos armazenados em geladeira ajusta-se a uma equação quadrática. Estes dados revelam que esses ovos não apresentam qualidade para ser consumido. Os ovos vermelhos quando estocados em geladeira apresentam-se viáveis durante todo período analisado. Comparando os ovos brancos e vermelhos estocados a temperatura ambiente, observa-se que os ovos brancos adéquam-se a uma equação cúbica, com baixa viabilidade aos 15 dias. Conclui-se que o armazenamento deve ser realizado em geladeira independente da coloração da casca dos ovos.
\end{abstract}

Palavras-chaves: Armazenamento.Qualidade do ovo. Tempo de prateleira.

\section{QUALITY AND CHARACTERISTICS OF COMMERCIAL EGG}

SUMMARY: The egg is a food with a high nutritional value, containing many proteins, vitamins and minerals, and low cost with which stimulates consumption. Due to be a perishable product is necessary to store it properly so that this product might be viable for the consumption for a long period. The objective of this research was to evaluate the internal quality of egg whites and reds at room temperature and stored under cooled during 25 days of storage. White and red eggs stored at room temperature with loss of viability to 15 days of storage, the eggs already stored in the refrigerator exhibit loss of viability with 25 days of storage. The viability of the white eggs stored in fridge fits a quadratic equation. These data show that these eggs do not have quality to be consumed. Red eggs when stocked in the fridge are viable throughout the analysis period. Comparing white and red eggs stored at room temperature, it is observed that the egg whites suited to a cubic equation, with low viability to 15 days. It is concluded that the store must be accomplished in the fridge regardless of the color of the egg shell.

Keywords: Storage. Trade of eggs. Food self life.

\section{INTRODUÇÃO}

O ovo é um alimento de grande valor nutritivo e recomendado para uma dieta variada e equilibrada (PLETI et al., 2009). Atualmente, o consumo per capita de ovos no Brasil corresponde a cerca de 160 ovos por habitante por ano, considerado baixo quando comparado com o Japão com consumo de 360 ovo/hab/ano (SANTOS FILHO;SCHLINDWEIN, 2007).

Este produto é uma excelente fonte de proteína de baixo custo, podendo contribuir para melhorar a dieta de famílias de baixa renda (PASCOAL et al., 2008). Em geral ocorre maior consumo de ovos em domicílios com maior renda per capita, com maior número de moradores e

\footnotetext{
${ }^{1}$ Unigran

${ }^{2}$ UFGD
}

Nucleus Animalium, v.8, n.1, maio 2016 
com a mulher chefe de família inserida no mercado de trabalho (SANTOS et al., 2009) . Nas regiões Norte e Nordeste, foram constatados menores consumo de ovos pelas famílias do que nas outras regiões, o que foi atribuído a sua menor renda per capita (SANTOS FILHO; SCHLINDWEIN, 2007).

Nunes et al. (2009) descrevem o perfil do consumidor de ovos relatando que 76,3\% da população consomem ovo branco e $21,4 \%$ ovos vermelhos. Verificou-se também que 39,1\% da população compram ovos uma vez por semana e $21,4 \%$ duas vezes por semana. Estas compras por sua vez são feitas em supermercados (38\%), em mercearias (20,4\%), em mercadinhos $(15,4 \%)$, em bodegas $(7,1 \%)$, em granjas $(6,1 \%)$, em depósitos $(5,0 \%)$, em distribuidores $(2,5 \%)$ e em atacadistas $(2,3 \%)$, mantendo-se estes consumidores $(53,8 \%)$ fidelidade ao ponto de venda. $\mathrm{O}$ aumento do consumo de ovos foi acompanhado pela maior exigência do mercado no que tange a qualidade e durabilidade deste produto.

Alguns parâmetros são importantes para aumentar a vida de prateleira do ovo, fatores como tempo de armazenamento associado a temperatura de estocagem deste produto são preponderantes (MOURA et al., 2008). De modo geral a diminuição ou perda da qualidade do ovo está relacionada com o envelhecimento do mesmo, porém a falta de controle do tempo e da temperatura durante o período de estocagem acelera esse processo. Sendo assim se faz necessário a avaliação da qualidade interna externa dos ovos.

No Brasil a refrigeração dos os ovos comercializados não é obrigatória deste modo desde o momento da postura até a distribuição final, os ovos ficam expostos a temperatura ambiente e em alguns casos são refrigerados somente nas casas dos consumidores (XAVIER et al., 2008), o que pode ocasionar depreciação da qualidade interna (MOURA et al., 2008), como a perda de 3\% a $6 \%$ o peso dos ovos durante a estocagem (MELLO et al., 2010).

Objetivou-se com o trabalho avaliar o efeito da temperatura sobre a viabilidade de utilização de ovos com casaca branca e vermelha

\section{MATERIAL E MÉTODO}

O ensaio foi realizado no Centro Universitário da Grande Dourados - UNIGRAN, no laboratório de técnicas alimentícias. Foram adquiridos 72 ovos com peso aproximado de $60 \mathrm{~g}$ (36 brancos e 36 vermelhos) no comercio da região da Grande Dourados. Os ovos foram pesados em balança semi-análitica e separados em dois grupos (casaca branca e casaca vermelha) e depois cada grupo foram distribuídos em dois ambientes com temperatura diferentes (temperatura ambiente $20 \pm 6,0^{\circ} \mathrm{C}$ e sob-refrigeração $\pm 10 \pm 2,0^{\circ} \mathrm{C}$ ).

A viabilidade dos ovos foram avaliados através do peso respectivo de cada componente 
(clara, gema e casaca), a perda de peso e o $\mathrm{pH}$ da clara e gema. Os ovos foram quebrados no inicio do ensaio, aos 5, 10, 15, 20 e 25 dias. Estes ovos foram separados em clara, gema e casaca para pesagem. O peso respectivo de cada componente em relação ao peso dos ovos inteiro fizeram-se cálculos, gerando os resultados de relação clara/ovo, gema/ovo e casca/ovo. A perda de peso foi calculada, subtraindo o peso final após o armazenamento e o peso inicial, medido no primeiro dia de estocagem, divido pelo peso final. $\mathrm{O} \mathrm{pH}$ da clara e gema foi medido por pHmetro digital.

Para análise de tempo de estocagem e pH foi aplicado delineamento inteiramente casualisado em um esquema com dois tratamentos, correspondendo ao tempo inicial e final, com 25 dias de acondicionamento e três repetições. As análises de variância (ANOVA) e médias foram comparadas ao teste Tukey ( $\mathrm{p}<0,05$ ). Para avaliar o tempo (inicial, 5, 10, 15, 20 e 25dias) que os ovos brancos e vermelhos apresentavam-se aptos para o consumo foi realizado a análise de regressão polinomial sob duas condições de armazenagem (ambiente e geladeira).

\section{RESULTADO E DISCUSSÃO}

As variáveis de perda de peso, relação albúmen/ovo, gema/ovo e casca/ovo estocados em temperatura ambiente e em geladeira durante 25 dias não apresentaram diferença estatística (Tabela 1). Numericamente observa-se que a perda de peso para ovos brancos e vermelhos armazenados em temperatura ambiente foram superiores aos mesmos armazenados em refrigeração. O tempo de estocagem é o fator determinante para perda de peso de ovos independente da temperatura de estocagem (MOURA et al., 2008; SANTOS et al., 2009). A perda de peso dos ovos armazenados deve ser atribuída a perda de água do albúmen, pois sua proporção diminui linearmente em função do período de estocagem, sendo significativamente mais acentuada nos ovos mantidos em temperatura ambiente (SANTOS et al., 2009). Notadamente, o tempo de estocagem em temperatura ambiente diminui o peso dos ovos independente da coloração da casaca.

A relação gema/ovo não apresentou diferença estatística m relação ao local de estocagem e a coloração da casaca dos ovos. Durante a abertura dos ovos observou-se que a gema também havia perdido consistência e conformação, devido ao período de estocagem. Alterações na forma e no peso das partes dos ovos são observadas para ovos estocados em temperatura ambiente (SANTOS et al., 2009; SEIBEL et al., 2005). 
Tabela 1. Avaliações físicas dos ovos brancos e vermelhos em diferentes tipos condições ambientes após 25 dias de estocagem.

\begin{tabular}{|c|c|c|c|c|}
\hline \multirow{3}{*}{$\begin{array}{l}\text { Variáveis } \\
\text { Perda de peso (g) }\end{array}$} & \multicolumn{2}{|l|}{ Ovos Brancos } & \multicolumn{2}{|l|}{ Ovos vermelhos } \\
\hline & Ambiente & Geladeira & Ambiente & Geladeira \\
\hline & $0,030 \pm 0,006$ & $0,020 \pm 0,003$ & $0,020 \pm 0,004$ & $0,016 \pm 0,003$ \\
\hline Relação albúmen/ovo & $0,490 \pm 0,015$ & $0,483 \pm 0,001$ & $0,497 \pm 0,010$ & $0,497 \pm 0,014$ \\
\hline Relação gema/ovo & $0,340 \pm 0,014$ & $0,368 \pm 0,008$ & $0,348 \pm 0,006$ & $0,322 \pm 0,008$ \\
\hline Relação casca/ovo & $0,163 \pm 0,004$ & $0,148 \pm 0,004$ & $0,167 \pm 0,006$ & $0,153 \pm 0,005$ \\
\hline
\end{tabular}

Letras distintas reportam diferença estatística pelo teste de Tukey (p>0,05)

Os ovos brancos armazenados em temperatura ambiente apresentam perda de viabilidade aos 15 dias de estocagem, já os ovos armazenados em geladeira apresentam perda de viabilidade para o consumo com 25 dias de estocagem. Contudo o armazenamento dos ovos brancos em geladeira estão adequados a uma equação quadrática. Estes dados revelam que esses ovos não apresentam qualidade para ser consumido (Figura 2. A). Os ovos vermelhos tornam-se inviáveis aos 15 dias de estocagem a temperatura ambiente. Já quando estocados em geladeira apresentamse viáveis durante todo período experimental (Figura 2. B).

Comparando os ovos brancos e vermelhos estocados a temperatura ambiente, observa-se que os ovos brancos adéquam-se a uma equação cúbica, com baixa viabilidade aos 15 dias, e após uma queda pronunciada até $100 \%$ de ovos inviáveis (Figura 2. C). Constata-se que os ovos brancos e os vermelhos armazenados em geladeira apresentaram adequações diferenciadas ao teste de regressão. $\mathrm{O}$ armazenamento de ovos brancos perdeu sua viabilidade a partir dos 25 dias. Os ovos vermelhos nesta condição de armazenamento apresentaram viabilidade de $100 \%$ durante o período de estocagem (Figura 2. D).

FIGURA 1. Percentual de ovos viáveis em (A) brancos e (B) vermelhos expostos a diferentes locais de armazenamento; ovos (C) armazenamento a temperatura ambiente e (D) armazenamento em geladeira.

Viabilidade de utilização de ovos brancos (A), vermelhos (B), no ambiente (C) e na geladeira (D) durante 25 dias de armazenamento.

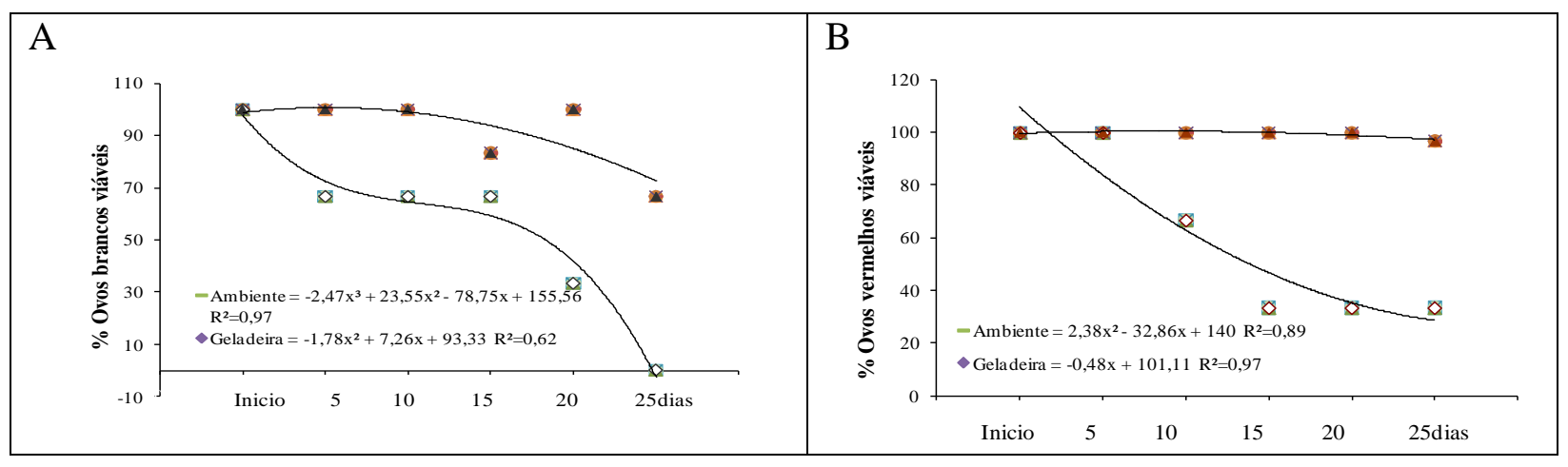

Nucleus Animalium, v.8, n.1, maio 2016 


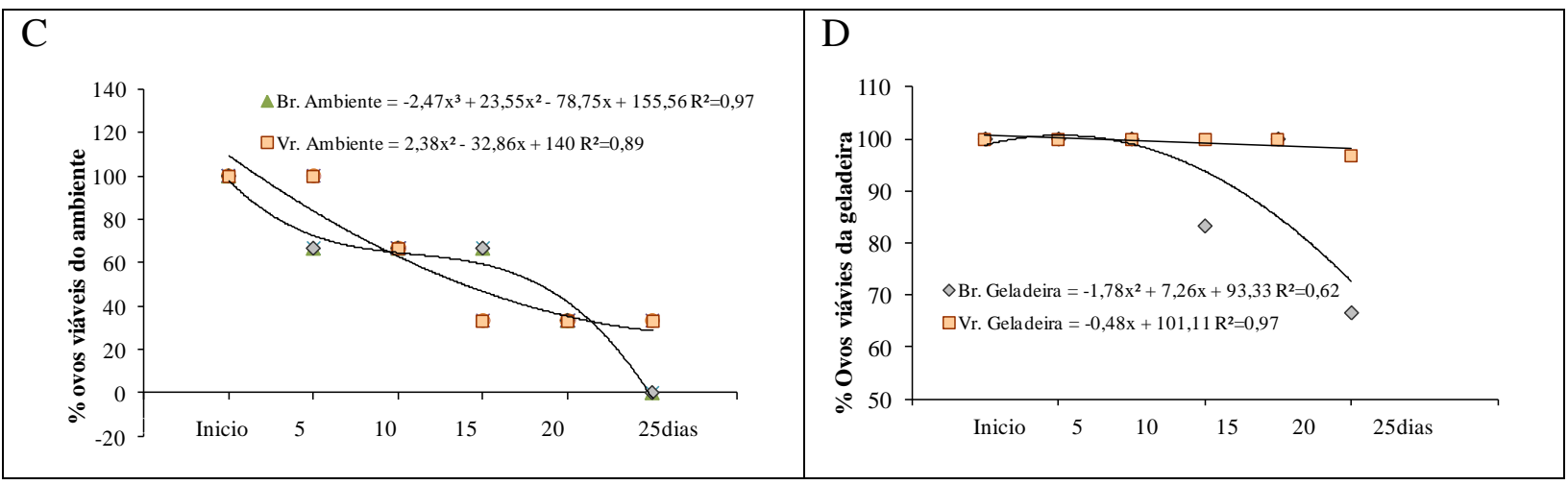

Jones e Musgrove (2005) descrevem que o armazenamento provoca perdas na qualidade dos ovos, no entanto as perdas mais pronunciadas são apresentadas para os ovos estocados em temperatura elevadas. Os autores também reforçam que até mesmo com 10 semanas de armazenamento com refrigeração a diminuição na altura do albúmen e maior incidência de ruptura da gema.

Os resultados das médias do $\mathrm{pH}$ da gema e clara de ovos brancos e vermelhos armazenados na temperatura ambiente e geladeira no primeiro e 25 dias de estocagem (figura $3 \mathrm{~A}$ e B). Os valores obtidos entre as colorações indica que os ovos vermelha apresentaram menor variação de $\mathrm{pH}$ em relação ao tempo e a temperatura (Figura 3A).

FIGURA 2 - Valores de pH da clara (A) e da gema (B) dos ovos brancos e vermelhos submetidos a diferentes condições de armazenamento Letras distintas (minúscula entre coloração dos ovos e maiúscula entre local de armazenamento) reportam diferença estatística pelo teste de Tukey $(\mathrm{P}>0,05)$

A

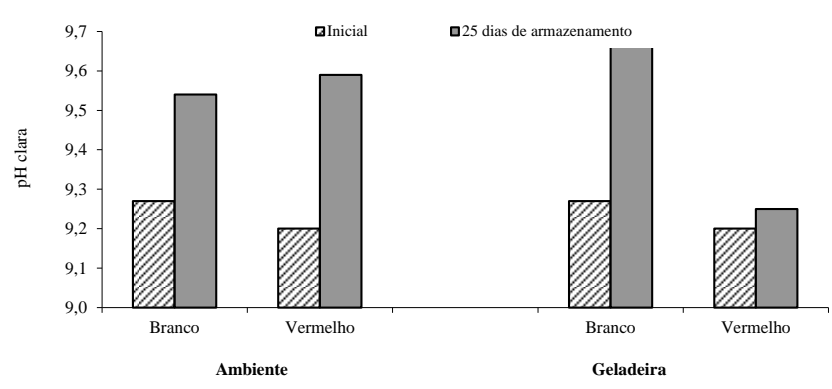

B

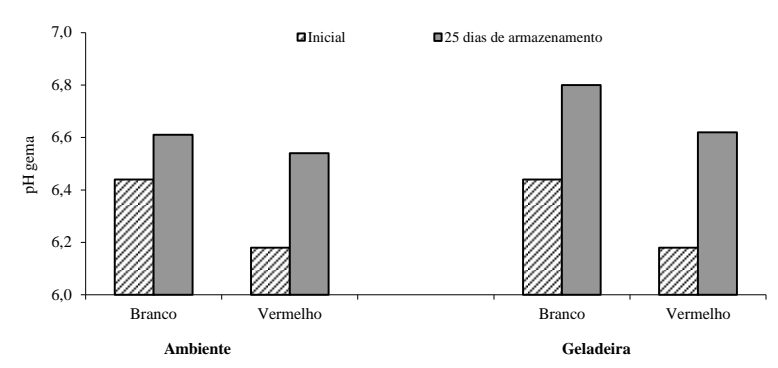

A coloração da casca dos ovos não foi um fator que contribui para diminuir as alterações de $\mathrm{pH}$. Comparando as médias dos ovos entre o as temperaturas constata-se que pH dos ovos estocados em temperatura ambiente apresentaram aumento de $\mathrm{pH}$ em relação aos os ovo armazenados na geladeira. As alterações no $\mathrm{pH}$ dos ovos armazenados na geladeira são decorrentes da diminuição no processo de oxidação devido a baixa temperatura (SEIBEL et al., 2005). O pH do álbum apresenta maiores variações quando estocados em temperatura ambiente 
(Pleti et al., 2009). O tempo de estocagem altera o sabor dos ovos devido alcalinzação do $\mathrm{pH}$ (SEIBEL et al., 2005). No entanto mesmo a refrigeração dos ovos não impede a deteriorização da qualidade principalmente da gema (Santos et al., 2009).

\section{CONCLUSÃO}

Os ovos que sofreram maior efeito do tempo foram os armazenados em temperatura ambiente aonde aos 15 dias de estocagem apresentaram perda de viabilidade. Em relação à coloração, os ovos vermelhos apresentaram os melhores valores em relação de conservação na qualidade interna. Recomenda-se o armazenamento deve ser realizado em geladeira independente da coloração da casca.

\section{REFERÊNCIAS}

AKYUREK, H.; OKUR, A.A. Effect of storage time, temperature and hen age on egg quality in free-range layer hens. Journal of Animal and Veterinary. v. 8, p. 1953-1958, 2009.

FILHO, J.J. Mitos e verdades sobre o colesterol de ovos de consumo. Disponível em: www.agroline.com.br/artigo.php?id=372 - 32k [2007]. Acessoem: 01 mar. 2009.

JONES, D.R.; MUSGROVE, M.T. Effects of extended storage on egg quality factors. Poultry Science, v.84, n.11, p.1774-1777, 2005.

LEANDRO, N. S. M.et al. Aspectos de qualidade interna e externa de ovos comercializados em diferentes estabelecimentos na região de Goiânia. Ciência Animal Brasileira, v.6, n.2, p.71-78, abr./jun. 2005 .

MELLO, C. L. R.; FREITAS, F.; PIRES, E. F. Conservação de ovos impermeabilizados com óleo mineral em temperatura ambiente. Revista Higiene Alimentar, v. 24, n. 188 /189, p. 180183, set. /out., 2010.

MOURA, A. A. M.et al.. Efeito da temperatura de estocagem do tipo de embalagem sobre a qualidade interna os ovos de codornas japonesas (CoturnixJaponica). Revista Ciência e Agrotecnologia, Lavras, v. 32, n. 2, p. 578 - 583, mar /abr., 2008.

NUNES, E. A. C.et al. Análise estatística da qualidade de ovos vermelhos, comercializados nos município de angelim, Garanhuns, Lagoa Do Ouro E São João - PE. Disponível em: http://www.eventosufrpe.com.br/eventosufrpe/jepex2009/cd/resumos/R0355-3.pdf. Acesso: maio de 2015

PASCOAL, L.A.F.et al. Qualidade de ovos comercializados em diferentes estabelecimentos na cidade de Imperatriz-MA. Revista Brasileira de Saúde Produção Animal, v.9, n. 1, p. 150-157, 2008 .

PLETI, A. K.et al. Qualidade interna do ovo de avestruz após a estocagem em temperatura ambiente e refrigerada. Revista Ciência Rural, Santa Maria, v. 39, n. 6, p. 1864 -1868, set., 2009. 
SANTOS, M. S. V.et al. Efeito da temperatura e estocagem em ovos. Ciência e tecnologia de alimentos, v. 29, n. 3, 2009.

SANTOS FILHO, J. I. SCHLINDWEIN, M. M. Fatores determinantes do consumo de ovos no Brasil. In: CONGRESSO DA SOBER, 45. 2007, Londrina. Disponível em: www.sober.org.br/palestra/6/727.pdf. Acesso em: 10 mar. 2009.

SEIBEL, N. F.et al. Qualidade física e química de ovos de codornas alimentadas com dietas modificadas. Revista Instituto Adolfo Lutz, v.64, n.1, p.58-64, 2005.

SIBIEL, N. F.; SOUZA-SOARES, L.A.; Avaliação física de ovos de codorna em diferentes períodos de armazenamento. Revista Vetor, Rio Grande, v. 13. P. 47-52, 2003.

SOUZA-SOARES, L. A.; SIEWERDT, F.; Aves e Ovos. $1^{\circ}$ edi. Pelotas, RS: Editora e Gráfica Universitária, 2005.

XAVIER, I. M. C.et al. Qualidade de ovos de consumo submetidos a diferentes condições de armazenamento. Revista Brasileira de Medicina Veterinária e Zootecnia, v.60, n.4. p.950-959, 2008 . 
